\title{
Stethoscopes with hearing aid use: Case studies
}

\section{Regina Tangerino de Souza Jacob', Ticiana Cristina de Souza Zambonato², Maria Fernanda Capoani Garcia Mondelli'.}

\author{
1) $\mathrm{PhD}$ in Communication Disorders at HRAC/USP. Professor, Department of Speech Pathology FOB / USP. \\ 2) $\mathrm{PhD}$ student in Communication Disorders at HRAC/USP. Speech Therapist, Hearing Health Division of HRAC / USP \\ Institution: Hearing Health Division of HRAC/USP, Faculty of Dentistry of Bauru/USP \\ Bauru / SP - Brazil \\ Mailing address: Regina Tangerino de Souza Jacob - Alameda Octávio Pinheiro Brizola 9-75 - Vila Universitária -Bauru/SP - Brazil - Zip code: 17012-901
}

Article received in August 24, 2010. Article accepted in February 5, 2011

\section{SUMMARY}

Introduction: Description for using stethoscopes adapted to hearing aids.

Aim: To describe the adaptation of HAs to stethoscopes used by 2 students in the health field with bilateral hearing impairment. Case reports: Two subjects with hearing loss had their stethoscopes coupled to HAs because of the individual requirements of their professions (healthcare) to perform auscultation.

Conclusion: The improvement was measured in situ, and satisfaction was evaluated using a subjective questionnaire. The use of a stethoscope coupled to an HA allowed students with hearing loss to perform auscultation.

Keywords: Stethoscopes; Hearing Aids; Hearing Loss.

\section{INTRODUCTION}

Hearing loss results in many limitations in the development of individuals. In countries such as Brazil with an unstable economic structure and an alarming unemployment rate, competition for jobs is immense. Moreover, the lack of information about disability coupled with the possible belief that disabled individuals will be less productive could result in questions about their capacity for work (1). Communication is indicative of the quality of life, and thus, deaf professionals need an inclusive society that allows them to work in various areas, including healthcare (2).

The Brazilian Census of 2000 identified 5,735,099 people with hearing impairment, a number greater than that of individuals with physical or mental disabilities and slightly lower than the number of people with motor disabilities (3). In a study conducted in Canoas (RS) (4), $6.8 \%$ of the local population was identified to have disabling hearing loss. Considering that the current Brazilian population consists of approximately 190 million people, more than 10 million individuals in this country have disabling hearing loss (over $41 \mathrm{~dB}$ ) (4).

Importantly, the new terminology of the World Health Organization published under the title "International Classification of Functioning Disability and Health-CIF" (5) suggests a possibility of change in the paradigm of health. This context no longer has the causation of diseases as object, considering their impact on quality of life. This classification emphasizes the positive aspects of the subject's health condition, and thus, its title was changed to incorporate functionality and health terms. Terms such as "impairment" or "handicaps" were abandoned, and the new classification uses functionality to refer to all body functions, activities, and participation. Similarly, the word "disability" is an umbrella term encompassing deficiencies, limitations of activities, and restriction in participation $(6,7)$.

In addition to the nonauditory consequences of the disability, there is a disadvantage imposed by hearing loss or auditory disability, which limits the individual's psychosocial functioning. Represented by social and emotional manifestations, the handicap/participation restriction can be strongly felt in the family and work environment $(8,9)$.

The use of a hearing aid (HA) associated with auditory rehabilitation can be considered a means of problem solving to minimize the difficulties (activity limitation) and disadvantages (participation restriction) experienced by individuals with hearing disabilities. Activity limitation refers to the difficulty faced by an individual in performing activities. Participation constraint refers to the problems that an individual may have in the form or extent of their involvement in everyday situations $(10,11)$.

In some work situations, individuals are reluctant to expose their hearing loss for fear that others will judge their inability. This is particularly true for health professionals such as doctors and nurses who need normal hearing to evaluate patients by auscultation (12). Auscultation is the hearing of sounds produced by the body. These sounds are 
due to the vibration of structures between their origin and the body surface. They can be captured directly by the examiner (direct auscultation) or with the aid of a stethoscope (indirect auscultation), and they can be evaluated by their intensity, frequency, and quality of sound (13).

The stethoscope is a device used to amplify body sounds such as those made by the heart and lungs (13). The apparatus consists of 2 ear tips that fit in the ear of the examiner, 1 or 2 conductor tubes through which sound is conducted, and a bell or diaphragm that is placed in the body of the examinee to amplify body sounds (14).

The use of the stethoscope usually represents a challenge for health professionals whouse HAs and cochlear implants (CIs) (14). For an effective adaptation, the stethoscope should be easy to manipulate and engage to the $\mathrm{HA}$ or $\mathrm{CI}$, portable, and able to faithfully reproduce the sounds of the body.

With this assumption, this study aimed to describe HAs fitted to stethoscopes used by 2 healthcare students with bilateral hearing loss.

\section{Case Report}

This study was approved by the Ethics and Research Committee under protocol n.043/2007. The subjects signed an informed consent form authorizing the release of the results.

The cases describe patients enrolled in the Division of Health Hearing of the Rehabilitation of Craniofacial
Anomalies Hospital, University of São Paulo, Bauru campus (DSA/HRAC/USP).

The subjects are students in the healthcare field, and they contacted the DSA with a complaint of being unable to hear through their HAs, which was essential for their ability to attend the university.

Thus, the DSA team referred them to an electronics technician who attached their stethoscopes to used analog behind the ear (BTE) hearing aid that were donated to the DSA.

Case 1: C was a 23-year-old female nursing student with slight sensorineural hearing loss (SNHL) on the right and deep SNHL on the left (Table 1). Hence, a BTE HA was used on her left ear and a mini BTE HA was used on her right ear.

Case2: S was a 22-year-old male medical student with moderate bilateral SNHL (Table 2). Hence, he used microchannel binaural HAs.

These students had stethoscopes for use in curricular internships; however, they had difficulty in using them because of their hearing loss. Thus, an electronics technician coupled their analog BTE HAs to their stethoscopes (Figure 1). This occurred after clarification of the procedures with the subjects and their families.

Two days were required to couple and deliver the stethoscopes with attached HAs to the students.

In both cases, the adaptation occurred in the right ear to attain the optimal audiometric thresholds, and it was

Table I. Audiometric thresholds of Case I.

\begin{tabular}{lccccccccc}
\hline & $250 \mathrm{~Hz}$ & $500 \mathrm{~Hz}$ & $\mathrm{I} \mathrm{Hz}$ & $2 \mathrm{~Hz}$ & $3 \mathrm{~Hz}$ & $4 \mathrm{~Hz}$ & $6 \mathrm{~Hz}$ & $8 \mathrm{~Hz}$ & \\
\hline AWRE & 65 & 65 & 50 & 35 & 40 & 45 & 35 & 45 & $\mathrm{~dB}$ \\
BRE & & 15 & 20 & 15 & 10 & 15 & & & $\mathrm{~dB}$ \\
AWLE & AUS & AUS & AUS & AUS & AUS & AUS & AUS & AUS & \\
BLE & & AUS & AUS & AUS & AUS & AUS & AUS & & \\
\hline
\end{tabular}

Legend: AWRE: Airway right ear; BRE: bone right ear; AWLE: Airway left ear; BLE: bone left ear; AUS: absent; Hz: Hertz; dB: decibel.

Table 2. Audiometric thresholds of Case 2.

\begin{tabular}{lccccccccc}
\hline & $250 \mathrm{~Hz}$ & $500 \mathrm{~Hz}$ & $\mathrm{IHz}$ & $2 \mathrm{~Hz}$ & $3 \mathrm{~Hz}$ & $4 \mathrm{~Hz}$ & $6 \mathrm{~Hz}$ & $8 \mathrm{~Hz}$ & \\
\hline AWRE & 30 & 35 & 50 & 65 & 70 & 70 & 75 & 80 & $\mathrm{~dB}$ \\
BRE & & 35 & 50 & 60 & AUS & AUS & & & $\mathrm{dB}$ \\
AWLE & 35 & 40 & 55 & 65 & 70 & 75 & 80 & 85 & $\mathrm{~dB}$ \\
BLE & & 35 & 50 & 60 & AUS & AUS & & & $\mathrm{dB}$ \\
\hline
\end{tabular}

Legend: AWRE: Airway right ear; BRE: bone right ear; AWLE: Airway left ear; BLE: bone left ear; AUS: absent; Hz: Hertz; dB: decibel. 
Table 3. Results of the Real Ear Insertion Gain (REIG).

\begin{tabular}{lccccccc}
\hline Frequencies & $250 \mathrm{~Hz}$ & $500 \mathrm{~Hz}$ & $\mathrm{IKHz}$ & $2 \mathrm{KHz}$ & $3 \mathrm{KHz}$ & $4 \mathrm{KHz}$ & \\
\hline REIG(Case I) & 26.2 & 31,6 & 43,6 & 39,4 & 30,1 & 34,6 & $\mathrm{~dB}$ \\
Target(Case I) 8,6 & 19,1 & 31,2 & 19,9 & 20,4 & 20,4 & $\mathrm{~dB}$ \\
REIG(Case 2) $\quad 14,3$ & 23,4 & 34,8 & 30,3 & 33,6 & 32,1 & $\mathrm{~dB}$ \\
Target(Case 2) $\quad 15, \mathrm{I}$ & 24,3 & 36,7 & 33,1 & 32,2 & 35,2 & $\mathrm{~dB}$ \\
\hline
\end{tabular}

necessary to use powerful analog BTE HAs to achieve effective auscultation with a stethoscope. As they had used HAs since childhood, they had no difficulties in handling the HA and mold, the latter being made exclusively for the use of this equipment. They were instructed on the procedure for auscultation directly by their teachers.

The assessment of real ear insertion gain (REIG) was performed using Affinity-Interacoustics equipment with comparisons to the gain prescribed by the NAL-NL1 (15) rule for each patient. We observed that the targets were achieved at all tested frequencies $(250-4000 \mathrm{~Hz})$, including low frequencies (Table 3). In the survey of electroacoustic characteristics using the same equipment, proper functioning of the HAs in accordance with the manufacturer's datasheet was confirmed.

Effective use of the device was made during the relevant internships during 1 semester, and after this experience, the students returned to DSA to complete the assessment of the satisfaction questionnaire related to the use of stethoscopes with HA adaptation.

\section{RESULTS}

It was noted in the questionnaire of satisfaction (Figure 2) to individuals that both subjects achieved auscultation, which was not possible only with HAs. There were no limitations on the use of the stethoscopes or performing the procedures. The subjects expressed a high degree of satisfaction and suggested disclosure of the coupling to students and healthcare professionals with hearing loss.

\section{DISCUSSION}

Healthcare professionals with hearing loss can use 2 types of stethoscopes: those with electronic amplification with the acoustic gain of $2-50 \mathrm{~dB}$ or those attached to HAs or CIs (17).

The mode of coupling will depend on the type of HA or IC processor (14-17). In the case of microchannel

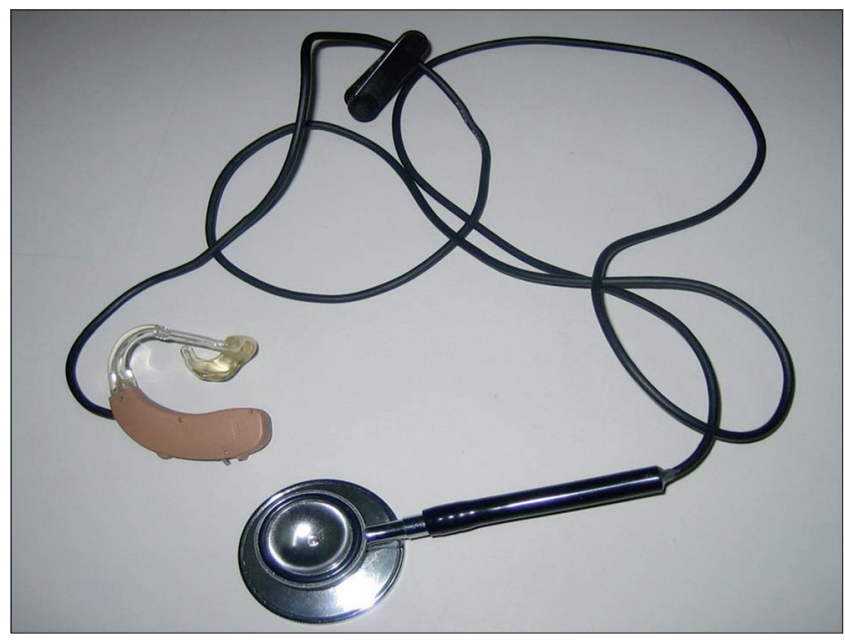

Figure 1. HA coupled to the stethoscope.

Answer the following questions considering their experience with the use of the stethoscope coupled to hearing aids, being $0=$ NEVER5 = ALWAYS

I - It was possible to listen with the stethoscope?

$\begin{array}{lllllll}\text { CASE I } & (\text { ) } 0 & (\text { ) l } & (\text { ) } 2 & \text { () } 3 & (\text { ) } 4 & (x) 5 \\ \text { CASE } 2 & (\text { ) } 0 & \text { ()। } & (\text { ) } 2 & (\text { ) } 3 & (\text { ) } 4 & \text { (x) } 5\end{array}$

2 - You could only listen with hearing aids?

$\begin{array}{lllllll}\text { CASE I } & (\mathrm{x}) 0 & (\text { ) } 1 & (\text { ) } 2 & (\text { ) } 3 & (\text { ) } 4 & \text { () } 5 \\ \text { CASE } 2 & (x) 0 & (\text { ) } 1 & (\text { ) } 2 & \text { () } 3 & (\text { ) } 4 & \text { () } 5\end{array}$

3 - Have you noticed limitations on the use of the stethoscope? What?
CASE I
$(x) 0$
() 1
( ) 2
() 3
( ) 4
() 5
CASE 2
$(x) 0 \quad() 1 \quad() 2$
() $3 \quad$ () $4 \quad$ ( ) 5

4 - You failed to conduct any due procedure stethoscope?

$\begin{array}{lllllll}\text { CASE I (x) } 0 & (\text { ) I } & (\text { () } 2 & \text { () } 3 & \text { () } 4 & \text { () } 5\end{array}$

CASE 2

$(\mathrm{x}) 0$

() $1 \quad() 2$

() 3

() 4 () 5

5 - Were you satisfied?

$\begin{array}{lllllll}\text { CASE I } & (\text { ) } 0 & (\text { ) I } & (\text { ) } 2 & \text { () } 3 & (\text { ) } 4 & \text { (x) } 5 \\ \text { CASE } 2 & (\text { ) } 0 & (\text { ) I } & (\text { ) } 2 & \text { () } 3 & \text { () } 4 & \text { (x) } 5\end{array}$

6 - You indicate the health of individuals with hearing impairment using the stethoscope?

$\begin{array}{lllllll}\text { CASE I } & (\text { ) } 0 & (\text { ) I } & (\text { ) } 2 & (\text { ) } 3 & (\text { ) } 4 & \text { (x) } 5 \\ \text { CASE } 2 & (\text { ) } 0 & \text { ()। } & (\text { ) } 2 & (\text { ) } 3 & (\text { ) } 4 & \text { (x) } 5\end{array}$

7 - Do you have any suggestions?

CASE 1: Check operation of the stethoscope on his wrist as standard.

CASE 2: Disclosure of equipment.

Figure 2. Results of the questionnaire used to verify the satisfaction of subjects. 
HAs or intracanal devices, the use of amplified stethoscopes (without HAs) or specific headphones for HAs is recommended; however, in this situation, the feedback often restricts the success of the adaptation. BTE users generally have a greater degree of hearing loss, and therefore, the gain offered by the amplified stethoscope is insufficient. Thus, the coupling of the stethoscope to an HA compatible with the needs of the subject, as demonstrated in the clinical cases described in this study, can be performed by an electronics technician or engineers through changes in the actual HAs or the use of fitted ear molds designed for that purpose, telecoil (being cords for electromagnetic induction or silhouettes), direct audio input, or frequency modulated systems.

Some aspects are fundamental for optimal use of the device, such as the type and degree of hearing loss, which must be considered to maximize the audibility of the low frequencies responsible for most of the sounds of the body (heart rate and murmurs between 20 to $150 \mathrm{HZ}$, some murmurs reaching $500 \mathrm{~Hz}$ or more, and breath sounds between 200 and $600 \mathrm{~Hz}$ ) (14-17).

A specific plan for the use of stethoscopes with an emphasis on low frequencies can be indicated in multi HAmemory, as well as a mapping of the IC that eliminates background noise, directing the microphone for the auxiliary connection (17), which was not necessary in present cases, as the 2 subjects used 2 different models of HAs, i.e., one was coupled exclusively to the stethoscope and used only during auscultation. Regarding this HA, it was observed that the prescribed gain was achieved for all tested frequencies (250-4000 Hz), including low frequencies.

In case 1, the gain insertion exceeded the target gain because of the patient's request, who felt more confident of the auscultation when it was performed at stronger intensities.

The use of a stethoscope with amplification or one compatible with the HA/IC is no guarantee for successful auscultation. Often, the individual will learn or relearn how to identify body sounds and distinguish them from external noises and distortions. Indications of strategies and computer programs for training as well as stethoscopes with screens for viewing the frequency waves or vibrotactile devices can be found on the Internet, and the subjects were guided regarding these resources.

The role of the speech pathologist responsible for fitting the HAs is to create conditions to reduce impairment in the performance of activities in the patient's daily life. This reduction in activity limitations can be documented using, among others, measures of subjective self-assessment. In many cases, it is possible to maximize the functionality of the individual concerning the activities when the clinician reviews the results of these assessments (7), for example, in the cases presented in which individuals were satisfied with their HA in daily situations, but this was not sufficient for performing their jobs properly in the academic environment.

\section{CONCLUSION}

The use of stethoscopes coupled to HAs enabled 2 students in the health field to perform the auscultation procedure, which was not possible only with HAs. The subjects reported satisfaction with this modified stethoscope.

\section{REFERENCES}

1. Tanaka EDO, Manzini EJ. O que os empregadores pensam sobre o trabalho da pessoa com deficiência? Rev Bras Ed Esp. 2005;11(2):273-94.

2. Chaveiro N, Barbosa MA. Assistencia ao surdo na área da saúde com fator de inclusão social. Rev Esc Enf. USP. 2005;39(4):417-22.

3. Instituto Brasileiro de Geografia e Estatística. Disponível em: www.ibge.gov.br, acesso realizado em 06/01/2009.

4. Raymann BCW, Béria JU, Gigante LP, Figueiredo AL, Jotz GP, Roithmann R, et al. Perda auditiva incapacitante e fatores sócio-econômicos: um estudo de base populacional em Canoas, RS, Brasil. Trabalho administrado em parceria com a Fundação ULBRA, Christoffel Blindenmission, Organização Mundial da Saúde, Fapergs (Fundação de Amparoà Pesquisa do Estado do Rio Grande do Sul) e Cnpq. Canoas (RS): Universidade Luterana do Brasil; 2004.

5. [OMS] Organização Mundial da Saúde, CIF: Classificação Internacional de Funcionalidade, Incapacidade e Saúde [Centro Colaborador da Organização Mundial da Saúde para a Família de Classificações Internacionais, org.; coordenação da tradução Cassia Maria Buchalla]. São Paulo: Editora da Universidade de São Paulo - EDUSP; 2003.

6. Buchalla CM. A Classificação Internacional de Funcionalidade,Incapacidade e Saúde. Acta Fisiátrica. 2003;10(1):29-31.

7. Morettin M, Bevilacqua, MC, Cardoso, MRA. A aplicação da Classificação Internacional de Funcionalidade, Incapacidade e Saúde (CIF) na Audiologia. Distúrb Comun, São Paulo. 2008;20(3):395-402.

8. Carvalho RM, Iório MCM. Eficácia da aplicação do 
questionário de handicap em idosos deficientes auditivos. Distúrb Comun. 2007;19(2):163-72.

9. Vuorialho A, Karinen P, Sorri M. Effect of hearing aids on hearing disability and quality of life in the elderly. International Journal of Audiology. 2006;45:400-5.

10. Magni C, Freiberger F, Tonn K. Avaliação do grau de satisfação entre usuários de amplificação de tecnologia analógica e digital. Rev Bras Otorrinolaringol. 2005;71(5):650-7.

11. Freitas CD, Costa MJ. Processo de adaptação de próteses auditivas em usuários atendidos em uma instituição pública federal - parte II: resultados dos questionários de auto-avaliação. Rev Bras Otorrinolaringol. 2007;73(5):660-70.

12. Patine FS, Barboza DB, Pinto MH. Ensino do exame físico em uma escola de enfermagem. Arq Ciênc Saúde. 2004;11(2):2-8.
13. Harry B. The inventor of stethoscope: René Laennec. J Family Practice. 1993;2(37):1-2.

14. Rennert NJ, Morris R, Barrere CC. How to cope with scopes: stethoscope selection and use with hearing aids and CIs. H Review [periódico online] 2004 [citado 2004 april 28]; [7 telas]. Disponível em: URL: http:// www.hearingreview.com/Articles.Asp?articleid=H0402F04. Acesso em: 06/01/2010.

15. Venema TH. The NAL-NL1 Fitting Method. Audiology on Line. 2001 feb. Disponível em: URL: http:// www.audiologyjournal.com. Acesso em 8 out de 2007.

16. Fabry DA. Clinical communication access through amplification for a medical student with severe hearing loss: case report. J Am Acad Audiol. 1993;4:426-31.

17. Association of Medical Professionals with Hearing Loss [Site na Internet]. Disponível em: URL: http:// www.amphl.org. Acesso em 8 out de 2007. 